\title{
On the Sensitivity of the Volume and Volatility of Bilateral Trade Flows to Exchange Rate Uncertainty*
}

\author{
Christopher F. Baum \\ Associate Professor, Department of Economics, Boston College, USA \\ DIW Research Professor, DIW Berlin, Berlin, Germany \\ Mustafa Caglayan \\ Professor, Department of Economics, University of Sheffield, UK
}

July 10, 2008

\begin{abstract}
We present an empirical investigation of the hypotheses that exchange rate uncertainty may have an impact on both the volume and variability of trade flows by considering a broad set of industrial countries' bilateral real trade flows over the period 1980-1998. Similar to the findings of earlier theoretical and empirical research, our first set of results shows that the impact of exchange rate uncertainty on trade flows is indeterminate. Our second set of results provides new and novel findings that exchange rate uncertainty has a consistent positive and significant effect on the volatility of bilateral trade flows, helping us better understand macroeconomic volatility.
\end{abstract}

JEL: F17, F31, C22.

Keywords: exchange rates, trade flow variability, volatility, trade flows.

*We gratefully acknowledge the British Academy's support under grant SG-39252 and the comments of seminar participants at Strathclyde University, University of Sheffield, Heriot-Watt University and the 2006 Forecasting Financial Markets Conference, Aix en Provence. We are grateful for constructive suggestions from an anonymous reviewer of this journal. The standard disclaimer applies. Corresponding author: Christopher F. Baum, Department of Economics, Boston College, Chestnut Hill, MA 02467 USA, Tel: +1-617-552-3673, fax +1-617-552-2308, e-mail: baum@bc.edu. 


\section{Introduction}

Since the breakdown of the Bretton Woods system of fixed exchange rates, a substantial body of theoretical and empirical literature has investigated the link between exchange rate uncertainty and international trade flows as this information contributes to our understanding of the transmission mechanism of exchange rate fluctuations on the economy. The general presumption is that an increase in exchange rate uncertainty will have an adverse effect on trade flows and consequently, the overall health of the world economy. However, neither theoretical models nor empirical studies provide us with a definitive answer.

An overview of the theoretical literature for the last two decades suggests that there is no clear-cut relationship one can pin down between exchange rate uncertainty and trade flows. Analytical results are based on specific assumptions and only hold in certain cases. ${ }^{1}$ Mirroring the diverse analytical findings, empirical research fails to reach firm conclusions: "...the substantial empirical literature examining the link between exchange-rate uncertainty and trade has not found a consistent relationship." (Bacchetta and van Wincoop (2000), p. 1093). The empirical results are, in general, sensitive to the choices of sample period, model specification, form of proxies for exchange rate volatility, and countries considered (developed versus developing). ${ }^{2}$

\footnotetext{
${ }^{1}$ Several theoretical studies (e.g., Clark (1973), Baron (1976)) have shown that an increase in exchange rate uncertainty will have adverse effects on the volume of international trade. Others, including Franke (1991), Sercu and Vanhulle (1992) have shown that exchange rate uncertainty may have a positive or ambiguous impact on the volume of international trade flows depending on aggregate exposure to currency risk (Viaene and de Vries (1992)) and the types of shocks to which the firms are exposed (Barkoulas, Baum and Caglayan (2002)). Also see models that study the impact of exchange rate uncertainty on trade and its welfare costs within a general equilibrium framework including Obstfeld and Rogoff (2003), Bacchetta and van Wincoop (2000).

${ }^{2}$ Negative effects of exchange rate uncertainty on trade flows are recently reported by Arize, Osang and Slottje (2000), Sauer and Bohara (2001) for developing countries, while Gagnon (1993) finds insignificant effects for developed countries. Baum, Caglayan and Ozkan (2004) report that the impact of exchange rate volatility on export flows differs in sign and magnitude across the countries studied. We should also note that researchers implementing gravity models (see Frankel and Wei (1993), Dell'Ariccia (1999), Rose (2000), and Tenreyro (2003) among others) have generally found a
} 
More recently Baum et al. (2004) rely on a nonlinear specification rather than linear alternatives while integrating the role of foreign income uncertainty in evaluating the impact of exchange rate uncertainty on bilateral trade flows between several developed countries. Although their findings are mixed, a subsequent analysis by Grier and Smallwood (2007) using a group of developed and developing countries finds a significant role in developing countries' exports for exchange rate uncertainty as well as a strong role for income uncertainty in most countries. ${ }^{3}$

In this paper, we present two sets of empirical findings motivated by the theoretical propositions of Barkoulas et al. (2002) that (i) exchange rate uncertainty affects the volume of trade flows and (ii) exchange rate uncertainty affects the variability of trade flows. Researchers generally motivate the first hypothesis indicating that exchange rate uncertainty will inevitably depress the volume of international trade by increasing the riskiness of trading activity. Contradictory empirical findings may result from the real options inherent in operating in such an uncertain environment. Regarding the second hypothesis - that the volatility of trade flows may be affected by exchange rate uncertainty — we must recognize that the volatility of trade flows may have real impacts upon exporters and importers' decision-making processes. Their ability to define optimal production plans, capital investment spending and financial leverage will all be hindered by a more uncertain environment for their trade-sensitive activities. ${ }^{4}$ The potential for trade flow uncertainty to exert serious effects on the macroeconomy is evident when we consider that export and import

negative relationship between exchange rate variability and trade. However, Clark, Tamirisa, Wei, Sadikov and Zeng (2004) indicate that 'this negative relationship, however, is not robust to a more general specification of the equation linking bilateral trade to its determinants that embodies the recent theoretical advances in a gravity model' (p. 2).

${ }^{3}$ One would be tempted to think that the exposure to unforeseen movements in exchange rates can be avoided using hedging. However, Wei (1999) finds no empirical support for the hypothesis that the availability of hedging instruments reduces the impact of exchange rate volatility on trade.

${ }^{4}$ For instance, according to Barkoulas et al. (2002), in open economies where the importance of international trade is sizable, variability of trade flows can significantly impact the variability of the overall level of economic activity resulting in 'financial sector illiquidity, reductions in real output, and/or heightened inflationary pressures' (p. 491). 
volatility is often several times that of aggregate output, as recognized by Engel and Wang (2007) and Zimmermann (1999). Hence, we consider the effects of exchange rate uncertainty on the volatility of trade flows as an important factor in the predictability of aggregate economic activity.

Our investigation concentrates on bilateral trade flows between 13 countries including the US, UK, Canada, Germany, France, Italy, Japan, Finland, Netherlands, Norway, Spain, Sweden, and Switzerland for the period 1980-1998 on a monthly basis in each direction. ${ }^{5}$ We investigate dozens of bilateral relationships and avoid the narrow focus on US data or the G7 countries' data that has characterized a number of bilateral studies. We implement a bivariate GARCH model on the first differences of exchange rate and trade volume data while taking into account that the trade flows may be affected by foreign output. Having generated internally consistent proxies for trade and exchange rate volatilities, we then investigate the impact of exchange rate uncertainty on the volume and volatility of bilateral trade flows.

Our analysis reveals two sets of findings. The first set of findings shows that the relationship between exchange rate uncertainty and bilateral trade flows is not clear. We find that only 30 out of 143 models tested yield statistically significant steady-state effects of exchange rate uncertainty on the volume of trade flows. We find a positive relationship in 23 models and a negative relationship in seven models. This observation should not be too surprising as the recent empirical literature has recorded similar findings. Furthermore, these results are in line with the theoretical literature. Our second set of findings is new and novel as we provide indirect empirical support to a proposition suggested in Barkoulas et al. (2002). Specifically, we show that exchange rate uncertainty has a meaningful empirical impact on the volatility of trade flows. We find that 81 out of 143 models tested provide support for a statistically significant steady-state effect of exchange rate uncertainty on trade volatility. We obtain a positive and significant relationship in 75 models and a neg-

\footnotetext{
${ }^{5}$ The sample considered ends in December 1998 at the launch of the Euro.
} 
ative and significant relationship in only six models. The median impact of a one standard deviation increase in exchange rate uncertainty on trade volatility is an economically meaningful $5.75 \%$ increase.

The rest of the paper is constructed as follows. Section 2 presents a summary of the literature on trade flow variability and motivates the empirical analysis that follows. Section 3 discusses the data set and the empirical model that we employ. Section 4 documents our empirical findings while Section 5 concludes and draws implications for future theoretical and empirical research.

\section{Motivation}

There is a long list of papers which focus on the effects of exchange rate variability on trade flows ${ }^{6}$ arguing that exchange rate uncertainty will inevitably depress the volume of international trade by increasing the riskiness of trading activity. Our twopronged empirical investigation is mainly motivated by Barkoulas et al. (2002) who utilize a partial equilibrium model to study the impact of exchange rate movements on the level and volatility of trade flows. They claim that an analysis considering the effects of exchange rate uncertainty only on the volume of trade will not be capable of generating predictions of managers' optimal behavior. Hence, they build their model to investigate two separate hypotheses: (i) does exchange rate uncertainty affect trade flows (first moment effects)? (ii) does exchange rate uncertainty impact trade flow variability (second moment effects)? Notably, few researchers have considered the second hypothesis despite the fact that the volatility of trade flows relative to that of aggregate output is sizable: often a factor of two or three times GDP volatility, and as volatile as investment spending.

The model that Barkoulas et al. (2002) construct assumes that managers' decisions to export (or import) depend upon both expected return and risk and suggests

\footnotetext{
${ }^{6}$ See notes 1 and 2 above.
} 
modeling the impact of exchange rate uncertainty on both the first and second moments of trade flows. In particular, their model identifies three sources of uncertainty which are associated with general microstructure shocks, the fundamental forces driving the exchange rate process, and a noisy process which provide signals regarding the future policy innovations. In a regime of flexible exchange rates, where exporters must form an optimal prediction of future spot rates when the information content of the signal changes, the model shows that as the variability associated with any of the three sources of uncertainty changes both the volume and variability of trade flows will be affected. One interesting aspect of their study helps reconcile the empirical ambiguity between exchange rate uncertainty and the volume of international trade. Although an increase in the variance of the general microstructure shocks dampens international trade, neither the variance of the fundamentals nor that of the noise will have a clear impact. The other interesting aspect of the model yields unambiguous associations between exchange rate variability and trade flow variability. While the variability of the general microstructure term and that of the noise have a clear negative impact on trade flow variability, an increase in the uncertainty of the fundamentals increases the variability of trade flows.

In our review of the literature on the variability of trade flows, we came across two studies which incorporate the volatility of trade flows to understand international business cycles. Although our hypothesis that uncertainty in trade flows arising from exchange rate uncertainty will have serious effects on the macroeconomy is different from those studies' emphasis, it would be useful to document some of the findings reported in them. In a recent contribution considering trade flow volatility, Engel and Wang (2007) lay out a two-country two-sector model to understand international real business cycles. They state that although countercyclical behavior of net exports is a well established fact, the literature has neglected the behavior of imports and exports which tend to be much more volatile than GDP. Hence, they incorporate this neglected feature into their model. To be specific, using quarterly data from 25 
OECD countries, they provide evidence that the standard deviations of imports and exports are about 2-3 times larger than that of GDP. However, their experiments using several related models lead them to believe that high volatility in international trade flows is unlikely to arise from volatility of exchange rates, despite the stylized fact that high volatility of exchange rates is a feature of the data. ${ }^{7}$ Instead, they focus on the role of trade in durable consumption goods to explain the volatility of trade flows assuming that while switching between home and foreign durable goods is highly costly in the short run, home and foreign goods are perfect substitutes in the long run. Their simulation results are generally supportive as their model captures the volatility of trade flows along with several other features of the data.

The second study is that of Zimmermann (1999). He, too, provides an international real business cycle model to explain the behavior of components of GDP and attempts to rationalize trade flow variability. He points out that trade flows are much more volatile than GDP - as volatile as investment - and that prior research has not addressed this issue. Using a three-country business cycle model he suggests that while there might be other variables playing a role, shocks to exchange rates may be relevant in explaining the observed volatility in trade flows. In his modeling effort, the role of exchange rates arises from the fact that it takes time for imports to be delivered and that the exchange rate relevant for invoicing is determined at delivery. He assumes no hedging. While his simulation exercises yield reasonable results relative to observed data, the results are sensitive to the choice of parameters.

In our empirical investigation below, we employ a simple reduced form model to understand how movements in real exchange rates affect the behavior of (i) the level and (ii) the volatility of exports. Although our study can best be described in the spirit of Barkoulas et al. (2002), we do not attempt to capture exchange rate

\footnotetext{
${ }^{7}$ Using a model in the spirit of Zimmermann (1999), Engel and Wang show that an increase in exchange rate volatility can be helpful in explaining the volatility in trade flows. But their construct yields a negative correlation between the levels of exports and imports, whereas that correlation is generally positive in the data.
} 
uncertainty that may arise from different sources. The empirical methodology that we use to generate a proxy for exchange rate uncertainty should be interpreted as a composite index for real exchange rate uncertainty. We construct our model in terms of first differences due to the time series properties of the variables in our regressions. We consider the possibility that the variables of interest may be cointegrated unit root processes, but find no empirical evidence supporting cointegration.

In the following sections, we discuss our data and the mechanism that generates measures of exchange rate and trade volatility as well as the model that we implement to test for the linkages between exchange rate uncertainty and the level and the volatility of trade flows.

\section{Data}

Our primary empirical investigation is carried out with monthly data on bilateral aggregate real exports, in each direction, over the period between January 1980 and December 1998 for 13 countries: US, UK, Canada, Germany, France, Italy, Japan, Finland, Netherlands, Norway, Spain, Sweden, and Switzerland. These data are constructed from bilateral export series available in the IMF's Directions of Trade Statistics (DOTS) and export price deflators, consumer price indices and monthly spot foreign exchange rates from the IMF's International Financial Statistics (IFS). The export data are expressed in current US dollars; they are converted to local currency units (LCU) using the spot exchange rate vis-à-vis the US dollar, and deflated by the country's export price deflator to generate real exports. The real exchange

rate is computed from the spot exchange rate and the local and US consumer price indices, and is expressed in logarithmic form. Since the series entering the computation of the real exchange rate are not seasonally adjusted, the $\log$ (real exchange rate) series are adjusted using seasonal dummies.

As a control variable in our analysis we also use measures of foreign GDP extracted 
from International Financial Statistics. To match the monthly frequency of export data, we must generate a proxy for monthly foreign GDP as the available data is on a quarterly basis. ${ }^{8}$ Hence, we apply the proportional Denton benchmarking technique (Bloem, Dippelsman and Maehle (2001)) to the quarterly real GDP series in order to produce monthly GDP estimates. The proportional Denton benchmarking technique uses the higher-frequency movements of an associated variable - in our case monthly industrial production - as an interpolator within the quarter, while enforcing the constraint that the sum of monthly GDP flows equals the observed quarterly total.

Prior to proceeding with our empirical analysis, we provide summary statistics on the variability of trade flows and how it compares to GDP volatility in Table 1. In particular, we observe that real export volatility among these trading partners is more than twice that of real GDP for all but the UK and Germany, and more than three times as large for four countries. Similarly, real import volatility is more than twice as large as that of real GDP for all but the US and Germany, and more than three times as large for six of the thirteen countries in the sample.

\subsection{Generating proxies for the volatility of trade volumes and real exchange rates}

In order to investigate the impact of real exchange rate uncertainty on the volume and volatility of trade flows, we must provide a proxy that captures the volatility of both the exchange rate and trade flow series. The volatility measures are estimated using a bivariate GARCH system for the real exchange rate and the volume of trade flow data. ${ }^{9}$ This strategy allows us to estimate internally consistent conditional variances of both series which we use as proxies for exchange rate and trade flow volatility.

\footnotetext{
${ }^{8}$ Although it would be possible to use monthly industrial production itself to generate such a proxy, we chose not to use industrial production in that context, since it provides a limited measure of overall economic activity.

${ }^{9}$ Alternatively, it is possible to use a moving standard deviation of the series. However, this approach induces substantial serial correlation in the constructed series.
} 
Prior to estimation of the GARCH system, it is crucial to scrutinize the time series properties of the data. Implementing the GARCH system without an appropriate characterization of the order of integration of the series would lead to spurious conclusions. Consequently, we subject these series to a rigorous analysis of their order of integration, and find that most of them can be characterized as unit root $(I(1))$ processes. We check those exchange rate and trade flow series that exhibit I(1) characteristics for the possibility of a long-run relationship. However, we fail to find any empirical evidence supporting cointegration. With this evidence, we include only the lags of first differences of log trade volume and log real exchange rate series and first differenced log foreign country GDP in our bivariate system. Denoting the first differences of the log real export series, log real exchange rate and log real GDP by $s_{t}, x_{t}$ and $y_{t}$, respectively, the bivariate GARCH model for bilateral trade volumes and real exchange rates takes the following form:

$$
\begin{aligned}
x_{t} & =\vartheta_{0}+\vartheta_{1} s_{t-1}+\vartheta_{2} x_{t-1}+\vartheta_{3} y_{t-1}+\omega_{t}+\vartheta_{4} \omega_{t-1} \\
s_{t} & =\theta_{0}+\theta_{1} s_{t-1}+\theta_{2} x_{t-1}+\eta_{t}+\theta_{3} \eta_{t-1} \\
\mathbf{H}_{t} & =\mathbf{C}^{\prime} \mathbf{C}+\mathbf{A}^{\prime} u_{t-1} u_{t-1}^{\prime} \mathbf{A}+\mathbf{B}^{\prime} \mathbf{H}_{\mathbf{t}-\mathbf{1}} \mathbf{B}
\end{aligned}
$$

The conditional mean of $\Delta \log$ trade volume, $x_{t}$ in equation $(1)$, is defined in terms of its own lag, the lagged $\Delta$ real exchange rate and lagged $\Delta$ foreign GDP with a moving average innovation of order one. Equation (2) defines the conditional mean of the $\Delta$ log real exchange rate $\left(s_{t}\right)$ as a function of its own lag and $\Delta$ lagged trade volume as well as a first-order moving average innovation. The vector of innovations is defined as $u_{t}=\left[\omega_{t}, \eta_{t}\right]^{\prime}$. The diagonal elements of $\mathbf{H}_{t}$ are the conditional variances of $\Delta \log$ real exchange rate, $\sigma_{x_{t}}^{2}$ and $\Delta \log$ trade volume, $\sigma_{s_{t}}^{2}$ respectively.

Following Karolyi (1995), the matrix $\mathbf{C}$ is parameterized as lower triangular while matrices $\mathbf{A}$ and $\mathbf{B}$ are $2 \times 2$ matrices, so that there are eleven estimated parameters in equation (3). We assume that the errors are jointly conditionally normal with zero means and conditional variances given by an $\operatorname{ARMA}(1,1)$ structure as expressed in 
equation (3). Note that the structure of Equation (3) allows the conditional variance of the exchange rate to have an effect on that of trade flows and vice versa. Overall, we believe that our system of equations provide a well-specified minimal framework which emulate the mean and the volatility of trade flow series we investigate in equations (4) and (5) where we take into account more complex dynamic relationships between the variables. ${ }^{10}$ The system is estimated using the multivariate GARCHBEKK model as implemented in RATS 6.35.

\subsection{Modeling the dynamics of the mean and the variance of trade flows}

In this study, we investigate two sets of relationships. Both sets of relationships require us to introduce lags of the independent variables to capture the delayed effects in each relationship. In particular, earlier research has shown that there may be considerable lags associated with the impact of exchange rate uncertainty on trade flows. Furthermore, we must take into account the dynamics of the dependent variable arising from the time lags associated with agents' decisions to purchase and the completion of that transaction. Hence, these two issues require us to use an estimated model which is computationally tractable and yet sufficiently flexible to capture the dynamic pattern that exists between the variables.

We employ the following distributed lag structure to study the relationship between trade flows and exchange rate uncertainty:

$$
x_{t}=\alpha+\varphi \sum_{j=1}^{6} \delta^{j} x_{t-j}+\beta_{1} \sum_{j=1}^{6} \delta^{j} \sigma_{s_{t-j}}^{2}+\beta_{2} \sum_{j=1}^{6} \delta^{j} y_{t-j}+\beta_{3} \sum_{j=1}^{6} \delta^{j} s_{t-j}+\xi_{t}
$$

where our interest focuses on the sign and significance of $\beta_{1}$. The lag parameter $\delta$ is set to a specific value to ensure dynamic stability in that relationship while

\footnotetext{
${ }^{10}$ Increasing the complexity of the bivariate GARCH model is not feasible in our context due to problems associated with convergence of a more complex structure. As the result of this estimation is only used to compute the conditional variance series, consistent point estimates of equations (1)-(3) are sufficient.
} 
we estimate a single coefficient associated with each of the variables expressed in distributed lag form: $\varphi, \beta_{1}, \beta_{2}$ and $\beta_{3}$, respectively. ${ }^{11,12}$

To study the impact of exchange rate uncertainty on the volatility of trade flows, we employ a similar model:

$$
\sigma_{x_{t}}^{2}=\alpha+\lambda \sum_{j=1}^{6} \delta^{j} \sigma_{x_{t-j}}^{2}+\phi_{1} \sum_{j=1}^{6} \delta^{j} \sigma_{s_{t-j}}^{2}+\phi_{2} \sum_{j=1}^{6} \delta^{j} y_{t-j}+\phi_{3} \sum_{j=1}^{6} \delta^{j} s_{t-j}+\zeta_{t}
$$

where the dependent variable is trade flow variability, $\sigma_{x_{t}}^{2}$. In this relationship we are interested in the sign and the significance of the coefficient of exchange rate volatility, $\sigma_{s_{t-j}}^{2}{ }^{13}$ Similar to the model presented in equation (4), we introduce the $\log$ real exchange rate $\left(s_{t}\right)$ as well as the first difference of log real GDP $\left(\Delta y_{t}\right)$ of the importing country as control variables into this basic relationship.

Before we present our empirical results, we should resolve one issue relating to the specification of Equation (1) versus that of Equation (4), both of which model the conditional mean of differenced log trade flows. The omission of distributed lag terms in Equation (1) is motivated by the need to estimate as simple a model as possible in the multivariate GARCH context. The omission of the $\sigma_{s_{t-j}}^{2}$ term from Equation (1) is motivated by the limitations of the GARCH-BEKK estimation methodology, which does not support GARCH-in-mean terms. However, we believe that this is a workable approach. In line with much of the prior research, the real exchange rate

\footnotetext{
${ }^{11}$ Values for $\delta$ above 0.4 tended to generate several models in which dynamic stability conditions are violated. Consequently, we tested $\delta$ values in the range of $(0.2,0.4)$. These results, which are available from the authors upon request, are similar to those we report here for $\delta=0.4$. We also experimented with lag length, and found that six lags were sufficient to capture the series' dynamics. Given the monthly frequency of the data and the large number of coefficients on highly correlated regressors to be estimated, we did not find that an unconstrained distributed lag approach produced usable nor dynamically stable estimates.

${ }^{12}$ Although $\beta_{1}$ is the coefficient of a generated regressor (Pagan, 1984; Pagan, 1986), inference on the existence of a significant $\beta_{1}$ coefficient is not hindered by that issue.

${ }^{13}$ We note that $\sigma_{s t}^{2}$ is a generated regressor, as is the dependent variable in this equation, which is an augmented autoregression. The presence of two generated regressors, each produced in the nonlinear context of a multivariate GARCH specification, may have consequences for the conventional estimates of coefficients' standard errors. To our knowledge the econometric literature has not addressed this problem.
} 
uncertainty term $\left(\sigma_{s_{t-j}}^{2}\right)$ is not found to be significant in Equation (4). Thus, omitting that term should not create meaningful bias in the multivariate GARCH estimation. The omission permits us to rely on the multivariate strategy, in which the volatilities of each variable are allowed to influence the other through the off-diagonal terms in the $\mathbf{A}$ and $\mathbf{B}$ matrices of Equation (3). Although not reported here, those offdiagonal terms are significantly different from zero in many of the estimated models, suggesting that reliance on a more flexible single-equation GARCH model would have greater costs than benefits.

\section{Empirical results}

\subsection{Timeseries properties of the data}

In the literature, it has commonly been assumed that trade volume series (real exports) and real exchange rates, in level or log form, are nonstationary $(I(1))$ processes given evidence from univariate unit root tests. Prior to estimating our system of equations, we test each series for a unit root using the modified log-periodogram regression test of Phillips (2007) as implemented in Baum and Wiggins (2001). We find that the overwhelming proportion of both log exchange rate and log trade flow series exhibit $I(1)$ characteristics while the log GDP series are $I(1)$ except for four instances. For the remainder of our analysis we keep those series that are clearly classified as $I(1)$ and drop the remaining series. In total, this approach causes us to discard 13 potential pairs out of a possible 156 cases. We then test if there is a long run relationship between the exchange rate, trade flow and foreign income series using an Engle-Granger regression on levels of the series. ${ }^{14}$ Failing to establish a cointegrating relationship between any of the pairs involved, we use the first differences of the series in our bivariate GARCH system as discussed above.

\footnotetext{
${ }^{14}$ The Engle-Granger methodology is appropriately robust to deviations from normality of the underlying series.
} 


\subsection{Generation of proxies for conditional variance}

We have employed the bivariate GARCH model described above to estimate $\mathbf{H}_{\mathbf{t}}$, the conditional covariance matrix of log real trade flows and log real exchange rates, for each point in time. ${ }^{15}$ There is clear evidence of non-constancy in the conditional variances for the vast majority of series estimated. Although the conditional covariance between GARCH errors is not currently employed in our analysis, it is important to note that this measure of contemporaneous correlation is generally nonzero, signifying that estimation of Equations (1)-(3) as a system is the preferred approach to modeling the two conditional variances.

We present two summary statistics, mean and interquartile range (IQR), for the three elements of the conditional covariance matrix: US exports in Table 2 and German exports in Table $3 .{ }^{16}$ In each of these tables, it is evident that the conditional variances of trade flows - in terms of either mean or interquartile range across the sample - differ quite widely across partner countries, while the conditional variances (and IQRs) of real exchange rates for the US are similar for most countries with the exception of Canada (perhaps reflecting the close economic relationship between those NAFTA partners). The conditional covariance is negative for all partners except Canada. Similarly, the conditional variance of German real exports is very small for partner countries US and Netherlands. The IQR of the conditional variance of the German real exchange rate is exceedingly small for the Netherlands, perhaps reflecting the close monetary links between those trading partners during the sample period.

\footnotetext{
${ }^{15}$ Detailed estimation results from the bivariate GARCH models, estimated with RATS 6.35, are available on request from the authors.

${ }^{16}$ These statistics for the other 11 exporting countries are available on request.
} 


\subsection{Regression results}

In this section we initially discuss our regression results on the effects of exchange rate volatility on trade flows. We then focus on the role of exchange rate volatility on trade flow volatility. In our discussion, we concentrate on the sign and the significance of point and interval estimates of $\beta_{1}$ and $\phi_{1}$ obtained from equations (4) and (5), along with their corresponding steady state values, to explain the effects of exchange rate volatility on the mean and variance of trade flows, respectively. We compute the steady state $\hat{\beta}_{1}^{S S}=\left(\hat{\beta}_{1} \sum_{j=1}^{6} \delta^{j}\right) /\left(1-\hat{\psi} \sum_{j=1}^{6} \delta^{j}\right)$ and the steady state $\hat{\phi}_{1}^{S S}=$ $\left(\hat{\phi}_{1} \sum_{j=1}^{6} \delta^{j}\right) /\left(1-\hat{\lambda} \sum_{j=1}^{6} \delta^{j}\right)$.

Given that we estimate dozens of bilateral relationships, Appendix Table A details the parameter estimates for each bilateral relationship. This table presents the exporting country (in the order US, UK, France, Germany, Italy, Netherlands, Norway, Sweden, Switzerland, Canada, Japan, Finland, Spain) and its trading partner, the impact of exchange rate volatility on trade, $\hat{\beta}_{1}$, the steady state impact of exchange rate volatility on trade flows, $\hat{\beta}_{1}^{S S}$, the impact of exchange rate volatility on trade volatility, $\hat{\phi}_{1}$ and the steady state impact of exchange rate volatility on trade volatility, $\hat{\phi}_{1}^{S S}$, as well as their corresponding $p$-values. Using this table, we provide and discuss the summary statistics pertaining to each exporting country in Tables 4 and 5 below. ${ }^{17}$

Table 4 presents summary information on our first set of results regarding the linkages between exchange rate volatility and trade flows from the exporter's perspective. The first column gives the exporting country in the order above. In column two we display the number of occurrences (out of a possible 12) that the impact of exchange rate uncertainty on trade flows is distinguishable from zero at the five per cent level, followed by the median value of $\hat{\beta}_{1}$. In the fourth column we present the number of occurrences that the corresponding steady state impact of exchange

\footnotetext{
${ }^{17}$ Regression estimates are computed with HAC (Newey-West) standard errors with six lags.
} 
rate volatility on trade flows is significant at five per cent. Column five presents the median $\hat{\beta}_{1}^{S S}$ when the coefficient is significant. The standard deviation of the conditional variance, $\bar{\tau}_{s}$, is calculated from the timeseries of each bilateral relationship. The figure given is averaged over those trading partners for which we have estimated significant steady-state effects. Finally the last column gives the median impact of exchange rate uncertainty on trade flows in percentage terms, computed as $100 \times\left(\hat{\beta}_{1}^{S S} \cdot \tau_{s}\right)$ for each bilateral relationship possessing a significant steady-state effect. The impact measure expresses the median impact (over that subset of trading partners) of a one standard deviation increase in exchange rate volatility on the transformed log level of trade flows. ${ }^{18}$

An evaluation of the literature reveals that researchers investigating the association between exchange rate volatility and trade flows have generally concluded that there is no systematic relationship between the two variables. We arrive at a similar observation. Inspecting the table, the first feature one notices is that the sign of the median significant $\hat{\beta}_{1}$ and that of its steady-state value is positive in nine cases and negative in four cases. The greatest number of significant effects (4) is registered by the US and Switzerland. When we consider the entire set of 143 bilateral models, we observe that only 30 models yield statistically significant steady-state effects of exchange rate volatility on the volume of trade flows. We find a positive relationship in 23 models and a negative relationship in seven models. ${ }^{19}$

In the last column of Table 4, we look at the median impact of exchange rate uncertainty on trade flows using the median steady state value of the impact of exchange rate volatility on trade flows. Overall, we observe that this effect ranges between $(-7.7 \%, 3.7 \%)$ : a one standard deviation increase in uncertainty (for the

\footnotetext{
${ }^{18}$ Note that the impact measures for each country are calculated using information from the country-pair regressions that yield a significant relationship. Hence, in most cases the magnitude of the impact factor could be due to the existence of one or two significant bilateral relationships. An example is that of Sweden whose median impact effect differs in sign from that of the steady-state coefficient.

${ }^{19}$ At the ten per cent level of significance, we find 39 nonzero coefficients: 31 positive, 8 negative.
} 
average trading partner) can lead to about a $7.7 \%$ fall in trade flows for Norway while it can lead to an expansion of $3.7 \%$ for the US. The median impact across all exporting countries is $0.9 \%$. In summary, these results suggest that although the sign of exchange rate uncertainty on trade is indeterminate, a modest positive impact of exchange rate uncertainty on trade predominates for the countries that are considered here.

Table 5 presents summary information on our second hypothesis which explains the linkages between exchange rate uncertainty and trade flow volatility from the exporter's perspective. The setup of the table is similar to that of Table 4 with one exception. Given that the dependent variable in equation (5) is the variability of trade flows and not its logarithm, we present a percentage impact measure in the last column. That is, the impact of a one standard deviation increase in exchange rate uncertainty on trade flow volatility for each bilateral relationship is computed as $100 \times\left(\hat{\phi}_{1}^{S S} \cdot \tau_{s} / \bar{\sigma}_{x_{t}}^{2}\right)$ where $\bar{\sigma}_{x_{t}}^{2}$ is the volatility of trade flows for that countrypair. The impact measure displayed is the median of those values across trading partners, and is expressed as a percentage of the exporting country's mean volatility of trade flows. We show that exchange rate volatility has an economically meaningful impact on the volatility of trade flows. We find that 81 out of 143 models tested provide support for a statistically significant steady-state effect of exchange rate volatility on trade volatility. We obtain a positive and significant relationship in 75 models and a negative and significant relationship in only six models. ${ }^{20}$ The greatest number of significant effects (10) is registered by Spain, all positive, followed by the US and Switzerland (eight each, with seven positive for each country). Given that the overwhelming majority of the models provide a positive relationship between exchange rate uncertainty and the volatility of trade flows, considering our findings in the light of Barkoulas et al. (2002), we conjecture that either the preponderance of

\footnotetext{
${ }^{20}$ At the ten per cent level of significance, we find 90 nonzero coefficients: 82 positive, eight negative.
} 
shocks to the exchange rate process are associated with shocks to the fundamentals or that fundamental shocks are larger or have a greater impact on the real exchange rate than other shocks. ${ }^{21}$

The impact of a one standard deviation increase in exchange rate volatility on trade volatility has a median estimated value of $5.75 \%$, ranging from $2.3 \%$ for the UK to $23.4 \%$ for Finland. The median effects are uniformly positive. These findings have strong implications for the behavior of exporters: increases in the volatility of trade flows will have marked effects on the value of their real options to export. Although those option values are only one of the countervailing forces on the volume of trade, the effects we detect are sizable enough to play a role in the expansion or contraction of trade.

Our findings also suggest that the predictability of trade flows will vary inversely with exchange rate volatility. The reliability of any forecasting model of trade volume will be weakened in times of heightened exchange rate volatility. Furthermore, exporters' ability to define optimal production plans, capital investment spending and financial leverage will all be hindered by a more uncertain environment for their trade-sensitive activities. In such circumstances, the potential for trade flow volatility to exert serious effects on the macroeconomy should be clear.

\section{Conclusions}

In this paper, we investigate the impact of exchange rates on the level and volatility of trade flows for a broad set of bilateral data. We first document that an overwhelming number of bilateral trade volume and real exchange rate series can be characterized as unit root processes, but that there is no long run relationship between the variables. We then generate internally consistent measures of trade and exchange rate volatility

\footnotetext{
${ }^{21}$ Given the policy implications of knowing the type of shocks that lead to trade volatility, we think that it would be useful to verify our conjecture. However the complexity of our methodology leads us to leave this issue for future investigation.
} 
employing a bivariate GARCH methodology. Using these proxies, we investigate the impact of exchange rate volatility on the mean and the variance of trade flows in the spirit of Barkoulas et al. (2002). Our first set of results suggest that the impact of exchange rate volatility on trade flows is indeterminate. Only a small number of models (30 out of 143) present significant relationships: significant and positive in 23 models and significantly negative in the remaining seven models. Given the earlier theoretical and empirical findings in the literature, these findings are not surprising.

Our second set of findings is new and novel as we investigate the relationship between exchange rate volatility and that of trade flows. We first show that bilateral trade volatility is higher than GDP volatility, a stylized fact earlier documented by Engel and Wang (2007) and Zimmermann (1999) for aggregate trade flows. We then run a simple dynamic model to see if exchange rate volatility leads to higher trade variability. We find that for 81 out of 143 potential models, exchange rate volatility exhibits a positive steady-state impact on the volatility of trade flows. In particular, we obtain a positive and significant relationship in 75 models and a negative and significant relationship in only six models. The median impact of a one standard deviation increase in exchange rate volatility on trade volatility is an economically meaningful $5.75 \%$ increase. Coupled with earlier findings from the literature, these results suggest that further investigation of the effects of exchange rate volatility on developed countries' trade volume is not likely to be fruitful. In contrast, the strong interactions we have detected among the volatilities of real exchange rates and trade volumes imply that further study of this relationship would be warranted, particularly with regard to the trade flows between developed and developing countries. 


\section{References}

Arize, C., Osang, T. and Slottje, D. J. (2000), 'Exchange Rate Volatility and Foreign Trade: Evidence from thirteen LDCs', Journal of Business Economics and Statistics 18, 10-17.

Bacchetta, P. and van Wincoop, E. (2000), 'Does exchange-rate stability increase trade and welfare?', American Economic Review 90, 1093-1109.

Barkoulas, J., Baum, C. F. and Caglayan, M. (2002), 'Exchange rate effects on the volume and variability of trade flows', Journal of International Money and Finance 21, 481-496.

Baron, D. P. (1976), 'Fluctuating exchange rates and pricing of exports', Economic Inquiry 14, 425-438.

Baum, C. F., Caglayan, M. and Ozkan, N. (2004), 'Nonlinear effects of exchange rate volatility on the volume of bilateral exports', Journal of Applied Econometrics 19, 1-23.

Baum, C. F. and Wiggins, V. (2001), 'Tests for long memory in a time series', Stata Technical Bulletin 10(57).

Bloem, A. M., Dippelsman, R. J. and Maehle, N. O. (2001), Quarterly National Accounts Manual: Concepts, Data Sources, and Compilation, International Monetary Fund, Washington.

Clark, P. B. (1973), 'Uncertainty, exchange risk, and the level of international trade', Western Economic Journal 11, 302-313.

Clark, P. B., Tamirisa, N. T., Wei, S.-J., Sadikov, A. M. and Zeng, L. (2004), A new look at exchange rate volatility and trade flows, IMF Occasional Papers 235, International Monetary Fund. Full version available at http://www.imf.org/external/np/res/exrate/2004/eng/051904.pdf.

Dell'Ariccia, G. (1999), 'Exchange rate fluctuations and trade flows: Evidence from the European Union', IMF Staff Papers 46(3), 315-334.

Engel, C. and Wang, J. (2007), International trade in durable goods: understanding volatility, cyclicality, and elastics, Globalization and Monetary Policy Institute Working Paper 03, Federal Reserve Bank of Dallas. available at http://ideas.repec.org/p/fip/feddgw/03.html.

Franke, G. (1991), 'Exchange rate volatility and international trading strategy', Journal of International Money and Finance 10, 292-307.

Frankel, J. A. and Wei, S.-J. (1993), Emerging currency blocs, NBER Working Papers 4335, National Bureau of Economic Research, Inc. 
Gagnon, J. E. (1993), 'Exchange rate variability and the level of international trade', Journal of International Economics 34, 269-287.

Grier, K. B. and Smallwood, A. D. (2007), 'Uncertainty and export performance: Evidence from 18 countries', Journal of Money, Credit and Banking 39(4), 965979.

Karolyi, G. (1995), 'A multivariate GARCH model of international transmissions of stock returns and volatility: The case of the United States and Canada', Journal of Business and Economics Statistics 13, 11-25.

Obstfeld, M. and Rogoff, K. (2003), Risk and exchange rates, in E. Helpman and E. Sadka, eds, 'Contemporary Economic Policy: Essays in Honor of Assaf Razin', Cambridge University Press, pp. 401-451.

Pagan, A. R. (1984), 'Econometric issues in the analysis of regressions with generated regressors', International Economic Review 25, 221-47.

Pagan, A. R. (1986), 'Two stage and related estimators and their applications', Review of Economic Studies 53, 517-38.

Phillips, P. C. (2007), 'Unit root log periodogram regression', Journal of Econometrics 127(1), 104-124.

Rose, A. K. (2000), 'One money, one market: The effect of common currencies on trade', Economic Policy 15, 9-45.

Sauer, C. and Bohara, A. (2001), 'Exchange Rate Volatility and Exports: Regional Differences between Developing and Industrialized countries', Review of International Economics 9, 133-152.

Sercu, P. and Vanhulle, C. (1992), 'Exchange rate volatility, international trade, and the value of exporting firm', Journal of Banking and Finance 16, 152-182.

Tenreyro, S. (2003), On the trade impact of nominal exchange rate volatility, Working Papers 03-2, Federal Reserve Bank of Boston.

Viaene, J. M. and de Vries, C. G. (1992), 'International trade and exchange rate volatility', European Economic Review 36, 1311-1321.

Wei, S.-J. (1999), 'Currency hedging and goods trade', European Economic Review 43(7), 1371-1394.

Zimmermann, C. (1999), 'International business cycles and exchange rates', Review of International Economics 7(4), 682-98. 
Table 1: GDP, Export and Import Volatility

\begin{tabular}{llllll}
\hline \hline & GDPvol & RXvol & RX/GDP & RMvol & RM/GDP \\
\hline US & 0.1400 & 0.3167 & 2.2618 & 0.2770 & 1.9778 \\
UK & 0.1407 & 0.2756 & 1.9592 & 0.3048 & 2.1665 \\
FR & 0.1164 & 0.3514 & 3.0198 & 0.3663 & 3.1477 \\
DE & 0.2030 & 0.3140 & 1.5466 & 0.3118 & 1.5359 \\
IT & 0.1452 & 0.3729 & 2.5680 & 0.3860 & 2.6581 \\
NL & 0.1225 & 0.3248 & 2.6513 & 0.3330 & 2.7183 \\
NO & 0.1170 & 0.3446 & 2.9450 & 0.5289 & 4.5198 \\
SE & 0.1088 & 0.2823 & 2.5951 & 0.3368 & 3.0963 \\
CH & 0.0909 & 0.3458 & 3.8057 & 0.3020 & 3.3235 \\
CA & 0.1114 & 0.3895 & 3.4950 & 0.4118 & 3.6951 \\
JP & 0.1695 & 0.4700 & 2.7726 & 0.3489 & 2.0581 \\
FI & 0.1326 & 0.3563 & 2.6864 & 0.4135 & 3.1175 \\
ES & 0.1834 & 0.5783 & 3.1532 & 0.4588 & 2.5013 \\
\hline \hline
\end{tabular}

Notes: GDPvol, RXvol and RMvol represent the timeseries volatilities of real GDP, real exports and real imports, respectively, for each exporting country. Real export and real import volatilities are averaged over the other 12 trading partners. The ratio RX/GDP $(\mathrm{RM} / \mathrm{GDP})$ is the ratio of averaged real export (import) volatility to GDP volatility. 
Table 2: Conditional variance and covariance estimates for US exports

\begin{tabular}{lcccccc} 
Impt. & $\bar{\sigma}_{x_{t}}^{2}$ & $\bar{\sigma}_{s t}^{2}$ & $\overline{\text { covar }}$ & IQR $\sigma_{x_{t}}^{2}$ & IQR $\sigma_{s t}^{2}$ & IQR covar \\
\hline UK & 14.1708 & 1.1265 & -0.5936 & 8.9923 & 0.3687 & 0.7359 \\
FR & 21.0839 & 1.1301 & -0.9634 & 5.6093 & 0.3059 & 0.6390 \\
DE & 13.3683 & 1.1002 & -0.6617 & 3.4417 & 0.2826 & 0.6185 \\
IT & 21.9293 & 1.0084 & -0.9362 & 6.3705 & 0.5801 & 0.4453 \\
NL & 20.7567 & 1.1525 & -0.8000 & 7.6691 & 0.4194 & 0.8442 \\
NO & 60.7484 & 0.9234 & -0.3124 & 3.1260 & 0.3999 & 0.9437 \\
SE & 47.5715 & 1.0615 & -0.7459 & 8.9314 & 0.4460 & 1.0050 \\
CH & 15.4412 & 1.3318 & -1.0650 & 0.0641 & 0.0384 & 0.0323 \\
CA & 6.3278 & 0.1782 & 0.0570 & 0.1818 & 0.0421 & 0.0649 \\
JP & 10.2574 & 1.2339 & -0.7748 & 2.0631 & 0.2089 & 0.4079 \\
FI & 100.9517 & 1.0392 & -0.6857 & 21.2890 & 0.2933 & 1.4619 \\
ES & 33.4415 & 1.0442 & -0.2191 & 17.1623 & 0.3530 & 0.5396 \\
\hline
\end{tabular}

Notes: Impt. denotes the importing country. $\bar{\sigma}_{x_{t}}^{2}$ is the mean conditional variance $\times 1000$ of the $\log$ real export series. $\bar{\sigma}_{s_{t}}^{2}$ is the mean conditional variance $\times 1000$ of the log real exchange rate series. $\overline{\text { covar }}$ is the mean covariance $\times 1000$. The latter three columns contain the interquartile range $(\mathrm{IQR}) \times 1000$ of the same three series.

Table 3: Conditional variance and covariance estimates for DE exports

\begin{tabular}{lcccccc} 
Impt. & $\bar{\sigma}_{x_{t}}^{2}$ & $\bar{\sigma}_{s t}^{2}$ & $\overline{\text { covar }}$ & IQR $\sigma_{x_{t}}^{2}$ & IQR $\sigma_{s t}^{2}$ & IQR covar \\
\hline US & 8.3754 & 1.1218 & 0.1074 & 2.2708 & 0.1517 & 0.2926 \\
UK & 12.8806 & 0.7160 & 0.0164 & 4.8917 & 0.2979 & 0.7876 \\
FR & 18.6014 & 0.0925 & -0.1299 & 3.1398 & 0.0166 & 0.0879 \\
IT & 28.4438 & 0.3256 & 0.2685 & 3.4079 & 0.2556 & 0.4054 \\
NL & 8.9982 & 0.0406 & -0.0833 & 1.1120 & 0.0116 & 0.0756 \\
NO & 23.3325 & 0.2413 & 0.1989 & 8.0113 & 0.0895 & 0.2176 \\
SE & 13.2945 & 0.4827 & -0.1450 & 1.7845 & 0.0949 & 0.2099 \\
CH & 13.0135 & 0.1886 & -0.1252 & 2.5898 & 0.0511 & 0.1937 \\
CA & 23.3252 & 1.1811 & 0.2170 & 6.6720 & 0.2509 & 0.8468 \\
JP & 13.5483 & 0.9318 & -0.2637 & 4.8505 & 0.3748 & 0.4445 \\
FI & 21.7812 & 0.3943 & 0.0003 & 10.7657 & 0.2235 & 0.2888 \\
ES & 49.0591 & 0.3304 & 0.5662 & 2.8952 & 0.2469 & 0.5900 \\
\hline
\end{tabular}

Notes: see notes to Table 2. 
Table 4: Coefficient estimates and impact of $\beta_{1}$

\begin{tabular}{lcrcrrr} 
Expt. & \# Sig. & med sig $\hat{\beta}_{1}$ & \# Sig. & med sig $\hat{\beta}_{1}^{S S}$ & $\bar{\tau}_{s}$ & \% \\
\hline US & 4 & 136.978 & 4 & 106.659 & 0.234 & 3.674 \\
UK & 1 & 148.049 & 1 & 54.765 & 0.225 & 1.230 \\
FR & 2 & 190.664 & 2 & 78.356 & 0.331 & 0.995 \\
DE & 2 & 111.951 & 2 & 50.592 & 0.285 & 0.881 \\
IT & 3 & 180.295 & 3 & 72.953 & 0.434 & 3.344 \\
NL & 3 & 289.997 & 3 & 129.967 & 0.557 & 1.912 \\
NO & 1 & -683.136 & 1 & -324.047 & 0.238 & -7.719 \\
SE & 2 & 164.236 & 2 & 77.720 & 0.202 & 1.559 \\
CH & 4 & -307.299 & 4 & -159.119 & 0.322 & -1.998 \\
CA & 3 & -74.877 & 3 & -28.476 & 0.471 & -1.764 \\
JP & 3 & 136.280 & 3 & 50.618 & 0.250 & 0.615 \\
FI & 1 & 36.224 & 1 & 14.148 & 0.516 & 0.731 \\
ES & 1 & -51.989 & 1 & -23.975 & 0.511 & -1.226 \\
\hline
\end{tabular}

Notes: $\bar{\tau}_{s}$ is reported as $1000 \times$ the average standard deviation of $\sigma_{s_{t}}$.

Table 5: Coefficient estimates and impact of $\phi_{1}$

\begin{tabular}{lcrrrrr} 
Expt. & \# Sig. & med sig $\hat{\phi}_{1}$ & \# Sig. & med sig $\hat{\phi}_{1}^{\text {SS }}$ & $\bar{\tau}_{s}$ & \% Impact \\
\hline US & 7 & 12.887 & 8 & 9.111 & 0.316 & 7.315 \\
UK & 7 & 0.917 & 7 & 1.537 & 0.330 & 2.276 \\
FR & 4 & 2.182 & 3 & 2.908 & 0.338 & 4.345 \\
DE & 4 & 7.527 & 4 & 5.685 & 0.166 & 5.876 \\
IT & 4 & 2.087 & 4 & 2.161 & 0.441 & 3.462 \\
NL & 7 & 1.418 & 7 & 1.034 & 0.677 & 5.559 \\
NO & 5 & 38.905 & 7 & 24.580 & 0.291 & 3.347 \\
SE & 8 & 6.665 & 8 & 4.307 & 0.688 & 8.161 \\
CH & 7 & 4.343 & 7 & 5.219 & 0.257 & 5.751 \\
CA & 7 & 12.136 & 8 & 12.705 & 0.294 & 11.418 \\
JP & 6 & 2.691 & 6 & 3.866 & 0.415 & 3.476 \\
FI & 2 & 85.769 & 2 & 48.151 & 1.518 & 23.424 \\
ES & 9 & 3.863 & 10 & 3.736 & 0.446 & 9.340 \\
\hline
\end{tabular}

Notes: $\bar{\tau}_{s}$ is reported as $1000 \times$ the average standard deviation of $\sigma_{s_{t}}$. 
Table A. Regression estimates of $\beta_{1}, \phi_{1}$

\begin{tabular}{|c|c|c|c|c|c|c|c|c|c|}
\hline \multirow[b]{2}{*}{ Expt. } & \multirow[b]{2}{*}{ Impt. } & \multicolumn{3}{|c|}{ Real export equation } & \multicolumn{5}{|c|}{ Variance of real export equation } \\
\hline & & $\hat{\beta}_{1}$ & pval & $\hat{\beta}_{1}^{S S}$ & pval & $\phi_{1}$ & pval & $\hat{\phi}_{1}^{S S}$ & pval \\
\hline US & UK & 127.5389 & 0.000 & 109.6105 & 0.000 & 0.6747 & 0.012 & 1.2191 & 0.009 \\
\hline US & FR & 8.0260 & 0.846 & 3.1185 & 0.846 & 16.9454 & 0.000 & 11.4885 & 0.000 \\
\hline US & $\mathrm{DE}$ & -10.4587 & 0.710 & -4.0494 & 0.709 & 17.1813 & 0.000 & 8.9977 & 0.000 \\
\hline US & IT & 3.2470 & 0.895 & 1.2399 & 0.895 & -0.1696 & 0.061 & -0.3273 & 0.065 \\
\hline US & NL & 145.3827 & 0.012 & 103.7083 & 0.007 & 12.8865 & 0.000 & 10.3301 & 0.000 \\
\hline US & $\mathrm{NO}$ & -8.5907 & 0.833 & -3.4541 & 0.834 & 0.6714 & 0.651 & 0.4508 & 0.636 \\
\hline US & $\mathrm{SE}$ & 60.4194 & 0.101 & 26.5526 & 0.097 & 16.2156 & 0.000 & 9.2248 & 0.000 \\
\hline US & $\mathrm{CH}$ & 1895.9136 & 0.000 & 1172.5584 & 0.000 & 1.2633 & 0.000 & 0.7559 & 0.000 \\
\hline US & $\mathrm{CA}$ & 105.0681 & 0.518 & 51.7568 & 0.518 & 1.2581 & 0.188 & 0.8528 & 0.162 \\
\hline US & JP & 128.5742 & 0.021 & 49.7875 & 0.025 & -1.0224 & 0.350 & -0.7156 & 0.368 \\
\hline US & $\mathrm{FI}$ & 29.6171 & 0.737 & 12.7406 & 0.737 & 15.8181 & 0.068 & 10.9430 & 0.041 \\
\hline US & $\mathrm{ES}$ & -17.2052 & 0.539 & -9.4418 & 0.542 & -0.1593 & 0.018 & -0.3094 & 0.018 \\
\hline UK & US & -9.5148 & 0.524 & -4.3405 & 0.525 & 0.4748 & 0.333 & 0.3519 & 0.322 \\
\hline UK & FR & 8.2693 & 0.813 & 3.4035 & 0.812 & 0.8622 & 0.001 & 0.7646 & 0.000 \\
\hline UK & $\mathrm{DE}$ & 6.6265 & 0.741 & 2.8676 & 0.741 & 0.9166 & 0.000 & 1.6095 & 0.000 \\
\hline UK & IT & 148.0492 & 0.031 & 54.7653 & 0.027 & -11.6174 & 0.028 & -8.3073 & 0.035 \\
\hline UK & NL & 6358 & 0.139 & 77.9440 & 0.129 & 0.0336 & 0.960 & 0.0598 & 0.960 \\
\hline UK & $\mathrm{NO}$ & -20.4777 & & & & & & & 0.010 \\
\hline UK & $\mathrm{SE}$ & -6.9132 & 0.865 & -2.7623 & 0.865 & -0.6050 & 0.837 & -0.4514 & 0.839 \\
\hline UK & $\mathrm{CH}$ & 8.7345 & 0.767 & 3.4492 & 0.767 & 2.0737 & 0.011 & 1.6289 & 0.003 \\
\hline UK & $\mathrm{CA}$ & 75.9387 & 0.133 & 32.5653 & 0.136 & -5.6905 & 0.081 & -8.2131 & 0.089 \\
\hline UK & JP & -3.7247 & 0.809 & -1.4211 & 0.809 & 1.1947 & 0.000 & 2.0831 & 0.000 \\
\hline UK & FI & 12.6802 & 0.660 & & & -11.5583 & 0.015 & -12.8347 & 0.031 \\
\hline $\mathrm{FR}$ & US & -9.5286 & 0.813 & -9.0554 & 0.813 & 1.1074 & 0.007 & 0.8054 & 0.008 \\
\hline $\mathrm{FR}$ & UK & 23.2500 & 0.670 & 9.6777 & 0.669 & 1.9112 & 0.211 & 3.2437 & 0.196 \\
\hline FR & $\mathrm{DE}$ & 88.7292 & 0.522 & 37.9890 & 0.520 & 4.5977 & 0.173 & 4.8311 & 0.114 \\
\hline FR & $\mathrm{IT}$ & 56.9702 & 0.003 & 20.9740 & 0.003 & -0.3058 & 0.461 & -0.2342 & 0.487 \\
\hline FR & $\mathrm{SE}$ & 22.3497 & 0.261 & 10.9608 & 0.256 & -14.1609 & 0.098 & -13.1014 & 0.138 \\
\hline FR & $\mathrm{CH}$ & 324.3570 & 0.033 & 135.7379 & 0.031 & 10.7018 & 0.072 & 10.2068 & 0.065 \\
\hline $\mathrm{FR}$ & $\mathrm{CA}$ & -17.5138 & 0.912 & -6.7714 & 0.912 & -38.9023 & 0.000 & -208.8572 & 0.335 \\
\hline FR & JP & 7.0828 & 0.728 & 2.9981 & 0.727 & 3.2571 & 0.000 & 2.9084 & 0.000 \\
\hline FR & $\mathrm{FI}$ & -17.1568 & 0.680 & -7.3341 & 0.678 & 11.1044 & 0.302 & 13.3794 & 0.239 \\
\hline FR & $\mathrm{ES}$ & 170.5813 & 0.261 & 89.5034 & 0.272 & 15.1682 & 0.000 & 9.1468 & 0.000 \\
\hline $\mathrm{DE}$ & US & -7.9697 & 0.917 & -3.7066 & 0.917 & 4.2213 & 0.000 & 3.3781 & 0.000 \\
\hline $\mathrm{DE}$ & UK & -7.0313 & 0.681 & -2.7846 & 0.682 & -0.7538 & 0.424 & -1.1965 & 0.442 \\
\hline $\mathrm{DE}$ & $\mathrm{FR}$ & 1093.1518 & 0.075 & 453.1567 & 0.059 & 1.4778 & 0.960 & 1.0332 & 0.960 \\
\hline $\mathrm{DE}$ & $\mathrm{IT}$ & 50.0308 & 0.019 & 18.1229 & 0.019 & 7.3459 & 0.102 & 5.0608 & 0.085 \\
\hline $\mathrm{DE}$ & NL & -138.3491 & 0.721 & -160.4416 & 0.722 & 84.3006 & 0.000 & 78.0690 & 0.000 \\
\hline $\mathrm{DE}$ & $\mathrm{NO}$ & 119.5557 & 0.138 & 66.4902 & 0.142 & 1.6207 & 0.000 & 3.1303 & 0.000 \\
\hline
\end{tabular}


Appendix Table A, continued

\begin{tabular}{|c|c|c|c|c|c|c|c|c|c|}
\hline \multirow[b]{2}{*}{ Expt. } & \multirow[b]{2}{*}{ Impt. } & \multicolumn{3}{|c|}{ Real export equation } & \multicolumn{5}{|c|}{ Variance of real export equation } \\
\hline & & $\hat{\beta}_{1}$ & pval & $\hat{\beta}_{1}^{S S}$ & pval & $\phi_{1}$ & pval & $\hat{\phi}_{1}^{S S}$ & pval \\
\hline $\mathrm{DE}$ & $\mathrm{SE}$ & 173.8717 & 0.001 & 83.0620 & 0.001 & -1.9545 & 0.285 & -1.5910 & 0.306 \\
\hline $\mathrm{DE}$ & $\mathrm{CH}$ & -24.0496 & 0.817 & -10.0001 & 0.817 & 7.0714 & 0.234 & 5.3390 & 0.231 \\
\hline $\mathrm{DE}$ & $\mathrm{CA}$ & 48.5341 & 0.362 & 19.1585 & 0.358 & 2.5958 & 0.193 & 2.6362 & 0.166 \\
\hline $\mathrm{DE}$ & JP & -22.7532 & 0.460 & -9.0432 & 0.462 & 1.6337 & 0.193 & 1.4432 & 0.192 \\
\hline $\mathrm{DE}$ & FI & 19.6573 & 0.644 & 8.5917 & 0.644 & -7.3361 & 0.182 & -5.5440 & 0.203 \\
\hline $\mathrm{DE}$ & ES & 75.8886 & 0.099 & 33.1867 & 0.096 & 10.8328 & 0.000 & 7.9925 & 0.000 \\
\hline IT & US & 52.1149 & 0.322 & 47.5845 & 0.342 & 1.4533 & 0.000 & 2.7601 & 0.000 \\
\hline $\mathrm{IT}$ & UK & -9.5230 & 0.752 & -3.9100 & 0.752 & 12.9728 & 0.000 & 10.1123 & 0.000 \\
\hline $\mathrm{IT}$ & FR & 278.6395 & 0.019 & 116.2386 & 0.023 & 3.3149 & 0.345 & 2.3190 & 0.260 \\
\hline IT & $\mathrm{DE}$ & 21.6368 & 0.097 & 8.9463 & 0.097 & 2.6361 & 0.107 & 1.7334 & 0.066 \\
\hline IT & NL & 10.0464 & 0.323 & 4.5158 & 0.323 & -0.3181 & 0.356 & -0.2879 & 0.375 \\
\hline IT & $\mathrm{NO}$ & -99.3319 & 0.695 & -55.8875 & 0.697 & 9.6105 & 0.369 & 7.2785 & 0.372 \\
\hline $\mathrm{IT}$ & SE & 99.0038 & 0.005 & 43.2203 & 0.005 & -11.9772 & 0.135 & -10.2046 & 0.200 \\
\hline IT & $\mathrm{CH}$ & 180.2951 & 0.008 & 72.9529 & 0.011 & 2.7213 & 0.000 & 1.5609 & 0.000 \\
\hline IT & $\mathrm{CA}$ & 46.2028 & 0.529 & 17.7608 & 0.528 & 6.3833 & 0.230 & 6.6218 & 0.233 \\
\hline IT & JP & -2.4924 & 0.801 & -0.9964 & 0.800 & 1.1955 & 0.014 & 0.9491 & 0.022 \\
\hline IT & $\mathrm{ES}$ & 32.5881 & 0.348 & 13.4938 & 0.348 & 18.2978 & 0.314 & 15.1249 & 0.247 \\
\hline NL & US & -70.7127 & 0.143 & -31.5697 & 0.144 & & 0.000 & 634 & 0.000 \\
\hline NL & UK & 23.8564 & 0.271 & 10.1818 & 0.270 & 1.2735 & 0.036 & 0.9474 & 0.009 \\
\hline $\mathrm{NL}$ & $\mathrm{FR}$ & -15.5229 & 0.961 & -6.7625 & 0.961 & -9.3377 & 0.300 & -5.7754 & 0.305 \\
\hline NL & $\mathrm{DE}$ & 294.1492 & 0.378 & 129.4365 & 0.377 & 1.2069 & 0.663 & 2.3165 & 0.657 \\
\hline NL & IT & 18.8679 & 0.017 & 6.8431 & 0.016 & 1.4181 & 0.001 & 0.8549 & 0.000 \\
\hline NL & $\mathrm{NO}$ & 1109.9071 & 0.000 & 750.4896 & 0.000 & 13.9930 & 0.275 & 26.6971 & 0.257 \\
\hline NL & $\mathrm{SE}$ & 289.9969 & 0.001 & 129.9665 & 0.000 & -5.3270 & 0.026 & -3.6516 & 0.028 \\
\hline NL & $\mathrm{CH}$ & -131.8610 & 0.486 & -55.3111 & 0.486 & 24.5292 & 0.039 & 23.1783 & 0.037 \\
\hline NL & $\mathrm{CA}$ & -152.1797 & 0.073 & -60.6948 & 0.065 & 45.4683 & 0.000 & 22.1855 & 0.000 \\
\hline NL & JP & -34.2437 & 0.177 & -13.6751 & 0.176 & 0.7391 & 0.063 & 1.4202 & 0.068 \\
\hline NL & FI & 2.7198 & 0.702 & 1.0453 & 0.703 & 0.9426 & 0.006 & 1.0342 & 0.000 \\
\hline NL & ES & 9.2770 & 0.863 & 5.5844 & 0.863 & 1.2954 & 0.890 & 1.4536 & 0.889 \\
\hline $\mathrm{NO}$ & UK & -3.6783 & 0.906 & -1.4502 & 0.906 & 24.5130 & 0.000 & 24.5799 & 0.000 \\
\hline $\mathrm{NO}$ & $\mathrm{DE}$ & -103.5815 & 0.193 & -42.6480 & 0.190 & 3.9680 & 0.067 & 3.0379 & 0.040 \\
\hline $\mathrm{NO}$ & $\mathrm{IT}$ & 376.1189 & 0.463 & 141.5727 & 0.461 & 55.2500 & 0.000 & 80.5688 & 0.000 \\
\hline $\mathrm{NO}$ & $\mathrm{NL}$ & -63.6959 & 0.766 & -25.1009 & 0.765 & 38.9055 & 0.000 & 59.7641 & 0.000 \\
\hline $\mathrm{NO}$ & $\mathrm{SE}$ & 14.2178 & 0.352 & 6.1894 & 0.352 & 0.0419 & 0.000 & 0.0816 & 0.000 \\
\hline $\mathrm{NO}$ & $\mathrm{CH}$ & -72.4848 & 0.254 & -31.0537 & 0.254 & 5.3885 & 0.055 & 5.2451 & 0.032 \\
\hline $\mathrm{NO}$ & $\mathrm{CA}$ & -683.1357 & 0.004 & -324.0470 & 0.005 & 112.6550 & 0.000 & 78.7140 & 0.000 \\
\hline $\mathrm{NO}$ & FI & 40.3038 & 0.253 & 16.4890 & 0.246 & 1.4000 & 0.488 & 2.7571 & 0.495 \\
\hline SE & US & -24.8895 & 0.217 & -10.6355 & 0.213 & 2.0896 & 0.618 & 2.4991 & 0.591 \\
\hline $\mathrm{SE}$ & UK & 12.3273 & 0.733 & 5.4627 & 0.733 & 8.9565 & 0.000 & 9.1444 & 0.000 \\
\hline
\end{tabular}


Appendix Table A, continued

\begin{tabular}{|c|c|c|c|c|c|c|c|c|c|}
\hline \multirow[b]{2}{*}{ Expt. } & \multirow[b]{2}{*}{ Impt. } & \multicolumn{3}{|c|}{ Real export equation } & \multicolumn{5}{|c|}{ Variance of real export equation } \\
\hline & & $\hat{\beta}_{1}$ & pval & $\hat{\beta}_{1}^{S S}$ & pval & $\phi_{1}$ & pval & $\hat{\phi}_{1}^{S S}$ & pval \\
\hline SE & FR & 37.2038 & 0.107 & 15.5331 & 0.107 & -10.4534 & 0.000 & -8.2418 & 0.000 \\
\hline $\mathrm{SE}$ & $\mathrm{DE}$ & 163.3961 & 0.016 & 80.3401 & 0.013 & 35.4181 & 0.000 & 21.0606 & 0.000 \\
\hline $\mathrm{SE}$ & $\mathrm{IT}$ & 10.6183 & 0.207 & 4.0590 & 0.202 & 1.4252 & 0.000 & 1.6786 & 0.000 \\
\hline $\mathrm{SE}$ & $\mathrm{NL}$ & 165.0755 & 0.000 & 75.0994 & 0.000 & 5.8414 & 0.000 & 4.5579 & 0.000 \\
\hline SE & $\mathrm{NO}$ & 7.0107 & 0.403 & 2.8081 & 0.402 & 1.6796 & 0.000 & 1.8594 & 0.000 \\
\hline $\mathrm{SE}$ & $\mathrm{CH}$ & 49.9141 & 0.076 & 24.2276 & 0.066 & 7.4876 & 0.000 & 4.7872 & 0.000 \\
\hline $\mathrm{SE}$ & $\mathrm{CA}$ & -30.9216 & 0.247 & -13.2731 & 0.251 & 0.6549 & 0.453 & 1.4088 & 0.449 \\
\hline $\mathrm{SE}$ & JP & 10.6312 & 0.471 & 4.1244 & 0.472 & -1.3094 & 0.273 & -1.9874 & 0.286 \\
\hline $\mathrm{SE}$ & FI & 8.1896 & 0.750 & 3.5969 & 0.749 & 9.1613 & 0.037 & 4.0565 & 0.000 \\
\hline $\mathrm{CH}$ & US & -917.2439 & 0.005 & -794.8029 & 0.004 & -286.1580 & 0.000 & -529.3679 & 0.002 \\
\hline $\mathrm{CH}$ & UK & -39.0210 & 0.282 & -15.2746 & 0.283 & 4.3432 & 0.000 & 7.4768 & 0.000 \\
\hline $\mathrm{CH}$ & FR & 105.9346 & 0.423 & 45.1979 & 0.420 & 21.4967 & 0.110 & 18.9783 & 0.093 \\
\hline $\mathrm{CH}$ & $\mathrm{DE}$ & -17.6773 & 0.918 & -6.7733 & 0.918 & 34.3368 & 0.000 & 24.9804 & 0.000 \\
\hline $\mathrm{CH}$ & IT & 42.8454 & 0.025 & 15.2190 & 0.031 & 4.0043 & 0.001 & 3.4053 & 0.000 \\
\hline $\mathrm{CH}$ & $\mathrm{SE}$ & 90.6019 & 0.018 & 43.3218 & 0.021 & 11.7026 & 0.000 & 5.2188 & 0.000 \\
\hline $\mathrm{CH}$ & $\mathrm{CA}$ & -657.4442 & 0.029 & -333.4572 & 0.024 & 93.0659 & 0.164 & 163.5339 & 0.129 \\
\hline $\mathrm{CH}$ & JP & -5.7996 & 0.894 & -2.2721 & 0.894 & 4.3527 & 0.004 & 5.6002 & 0.004 \\
\hline $\mathrm{CH}$ & FI & -38.4297 & 0.727 & -15.5057 & 0.727 & 2.5931 & 0.000 & 5.0225 & 0.000 \\
\hline $\mathrm{CH}$ & ES & 66.4475 & 0.393 & 34.0860 & 0.390 & 0.6603 & 0.167 & 1.0232 & 0.149 \\
\hline $\mathrm{CA}$ & US & 203.5306 & 0.343 & 97.3222 & 0.343 & 3.7813 & 0.029 & 2.4824 & 0.025 \\
\hline $\mathrm{CA}$ & UK & -3.4383 & 0.923 & -1.4873 & 0.923 & 7.5754 & 0.123 & 5.4920 & 0.064 \\
\hline $\mathrm{CA}$ & $\mathrm{FR}$ & -59.8370 & 0.000 & -24.1415 & 0.000 & -1.5764 & 0.652 & -1.1057 & 0.651 \\
\hline $\mathrm{CA}$ & $\mathrm{DE}$ & -74.8771 & 0.021 & -28.4761 & 0.013 & 12.1362 & 0.000 & 15.0223 & 0.000 \\
\hline $\mathrm{CA}$ & IT & 35.7342 & 0.297 & 13.9696 & 0.302 & 11.3711 & 0.000 & 10.3879 & 0.000 \\
\hline $\mathrm{CA}$ & $\mathrm{NL}$ & -48.5916 & 0.451 & -20.2395 & 0.452 & 31.8487 & 0.000 & 20.9502 & 0.000 \\
\hline $\mathrm{CA}$ & $\mathrm{NO}$ & -19.0355 & 0.893 & -7.0674 & 0.893 & -62.6283 & 0.168 & -111.9961 & 0.181 \\
\hline $\mathrm{CA}$ & $\mathrm{SE}$ & 18.7819 & 0.418 & 7.8938 & 0.420 & 0.9175 & 0.052 & 1.6237 & 0.049 \\
\hline $\mathrm{CA}$ & $\mathrm{CH}$ & -101.6364 & 0.030 & -63.2391 & 0.022 & 9.8175 & 0.028 & 6.0852 & 0.032 \\
\hline $\mathrm{CA}$ & JP & 137.8106 & 0.242 & 59.2004 & 0.234 & 17.5561 & 0.000 & 17.6971 & 0.000 \\
\hline $\mathrm{CA}$ & FI & 69.6718 & 0.185 & 29.2071 & 0.181 & 24.8118 & 0.008 & 33.6191 & 0.014 \\
\hline $\mathrm{CA}$ & ES & 7.6140 & 0.804 & 3.1382 & 0.803 & 3.2891 & 0.218 & 3.6772 & 0.213 \\
\hline JP & US & 75.8871 & 0.001 & 31.6745 & 0.000 & -4.3169 & 0.272 & -4.1460 & 0.294 \\
\hline JP & UK & 136.2803 & 0.038 & 50.6176 & 0.036 & 0.0923 & 0.837 & 0.1681 & 0.837 \\
\hline JP & $\mathrm{FR}$ & -69.1934 & 0.366 & -24.6889 & 0.368 & -0.3363 & 0.876 & -0.6242 & 0.877 \\
\hline JP & $\mathrm{DE}$ & -24.1240 & 0.272 & -8.5367 & 0.272 & 2.5153 & 0.020 & 1.7032 & 0.013 \\
\hline JP & IT & -6.1096 & 0.663 & -2.0798 & 0.664 & 1.0337 & 0.035 & 1.4810 & 0.017 \\
\hline JP & NL & -36.7529 & 0.545 & -13.9820 & 0.546 & 0.7208 & 0.715 & 0.5174 & 0.714 \\
\hline JP & $\mathrm{NO}$ & 40.6675 & 0.299 & 23.0967 & 0.296 & 1.7798 & 0.715 & 2.4002 & 0.710 \\
\hline JP & $\mathrm{SE}$ & 9.9290 & 0.443 & 4.0226 & 0.443 & 1.8668 & 0.068 & 2.8444 & 0.061 \\
\hline
\end{tabular}


Appendix Table A, continued

\begin{tabular}{|c|c|c|c|c|c|c|c|c|c|}
\hline \multirow[b]{2}{*}{ Expt. } & \multirow[b]{2}{*}{ Impt. } & \multicolumn{3}{|c|}{ Real export equation } & & \multicolumn{4}{|c|}{ Variance of real export equation } \\
\hline & & $\hat{\beta}_{1}$ & pval & $\hat{\beta}_{1}^{S S}$ & pval & $\hat{\phi}_{1}$ & pval & $\hat{\phi}_{1}^{S S}$ & pval \\
\hline JP & $\mathrm{CH}$ & -28.8461 & 0.299 & -11.7808 & 0.299 & 2.5514 & 0.015 & 2.2616 & 0.008 \\
\hline JP & $\mathrm{CA}$ & -1.1401 & 0.981 & -0.4340 & 0.981 & 6.0666 & 0.001 & 7.1060 & 0.000 \\
\hline JP & FI & 44.9255 & 0.062 & 17.1676 & 0.061 & 2.8298 & 0.042 & 5.4709 & 0.049 \\
\hline JP & ES & 179.3128 & 0.001 & 96.7751 & 0.001 & 3.9221 & 0.000 & 6.5559 & 0.000 \\
\hline FI & US & 36.1323 & 0.171 & 15.2710 & 0.168 & -0.3325 & 0.389 & -0.2360 & 0.395 \\
\hline $\mathrm{FI}$ & UK & -2.6445 & 0.972 & -1.1357 & 0.972 & 4.6349 & 0.674 & 3.9535 & 0.671 \\
\hline $\mathrm{FI}$ & $\mathrm{FR}$ & 42.6493 & 0.242 & 17.5464 & 0.246 & 0.4705 & 0.276 & 0.5684 & 0.271 \\
\hline FI & $\mathrm{DE}$ & 24.3753 & 0.109 & 10.2247 & 0.105 & 8.0898 & 0.422 & 11.1876 & 0.284 \\
\hline FI & NL & 0.2858 & 0.861 & 0.1284 & 0.861 & 3.8450 & 0.000 & 1.9942 & 0.000 \\
\hline $\mathrm{FI}$ & $\mathrm{NO}$ & -19.3951 & 0.821 & -8.2605 & 0.821 & -8.3181 & 0.389 & -7.3732 & 0.406 \\
\hline FI & $\mathrm{SE}$ & 59.4242 & 0.099 & & & & 0.137 & & 0.136 \\
\hline $\mathrm{FI}$ & $\mathrm{CH}$ & 17.1064 & 0.540 & 7.1965 & 0.539 & 0.1189 & 0.847 & 0.1596 & 0.845 \\
\hline $\mathrm{FI}$ & $\mathrm{CA}$ & -67.2126 & 0.502 & -31.3908 & 0.506 & 167.6927 & 0.000 & 94.3069 & 0.000 \\
\hline $\mathrm{FI}$ & JP & 36.2239 & 0.046 & & 0.043 & 0.3001 & 0.830 & 0.1940 & 0.829 \\
\hline $\mathrm{ES}$ & US & -51.9889 & 0.026 & -23.9749 & 0.026 & 16.3940 & 0.000 & 8.9004 & 0.000 \\
\hline $\mathrm{ES}$ & UK & 17.7866 & 0.550 & 7.3817 & 0.551 & 0.7086 & 0.044 & 0.7238 & 0.021 \\
\hline $\mathrm{ES}$ & $\mathrm{FR}$ & 507.5590 & 0.158 & 186.1110 & 0.134 & -226.5816 & 0.467 & -207.2388 & 0.474 \\
\hline ES & $\mathrm{DE}$ & 8.8130 & 0.677 & 4.0211 & 0.677 & 2.3438 & 0.000 & 3.0648 & 0.000 \\
\hline ES & $\mathrm{IT}$ & -11.8182 & 0.480 & -4.5503 & 0.481 & 4.8387 & 0.174 & 3.1328 & 0.012 \\
\hline $\mathrm{ES}$ & NL & 7.7705 & 0.544 & 3.4624 & 0.544 & 3.8631 & 0.000 & 3.1925 & 0.000 \\
\hline ES & $\mathrm{NO}$ & 78.5861 & 0.262 & 39.2101 & 0.257 & 45.6240 & 0.027 & 41.5542 & 0.004 \\
\hline $\mathrm{ES}$ & $\mathrm{SE}$ & -3.8325 & 0.914 & -1.7781 & 0.915 & 1.8128 & 0.000 & 3.0753 & 0.000 \\
\hline $\mathrm{ES}$ & $\mathrm{CH}$ & 35.1306 & 0.402 & 23.8087 & 0.409 & 19.9823 & 0.000 & 11.9588 & 0.000 \\
\hline $\mathrm{ES}$ & $\mathrm{CA}$ & 68.2417 & 0.083 & 26.8258 & 0.081 & 0.7724 & 0.821 & 1.1845 & 0.820 \\
\hline ES & JP & -3.0258 & 0.909 & -1.0601 & 0.909 & 2.3751 & 0.000 & 4.2798 & 0.000 \\
\hline $\mathrm{ES}$ & FI & 1.0514 & 0.969 & 0.4132 & 0.969 & 70.4112 & 0.017 & 50.9498 & 0.002 \\
\hline
\end{tabular}

